\title{
Erratum to: 3D genomics imposes evolution of the domain model of eukaryotic genome organization
}

\author{
Sergey V. Razin ${ }^{1,2,3}$ • Yegor S. Vassetzky ${ }^{4,2,3}$
}

Published online: 15 December 2016

(C) Springer-Verlag Berlin Heidelberg 2016

Erratum to: Chromosoma

DOI: 10.1007/s00412-016-0604-7

An incorrect version of Figure 2 of this Article was inadvertently used.

The correct version of the figure appears below.

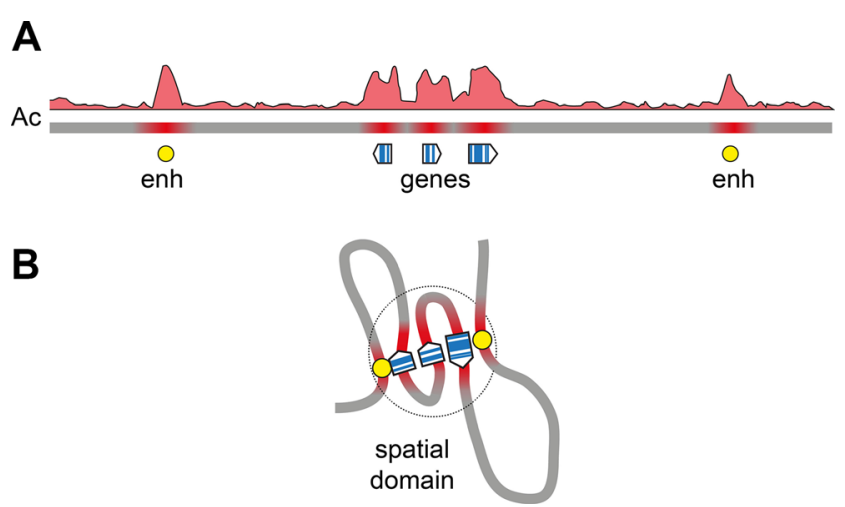

The online version of the original article can be found at doi:10.1007/s00412016-0604-7.

\footnotetext{
Yegor S. Vassetzky

vassetzky@igr.fr

Institute of Gene Biology RAS, Moscow, Russia

2 LIA1066 "French-Russian Cancer Research Laboratory", Villejuif, France

3 Lomonosov Moscow State University, Moscow, Russia

4 CNRSUMR8126, Université Paris Sud Paris Saclay, Institut Gustave Roussy, 39, rue Camille-Desmoulins, Villejuif 94805, France
} 